\title{
Artigos
}

\section{[DES]VELHECER, UMA REFLEXÃO SENSÓRIO-CÊNICA SOBRE A MULHER E O ENVELHECIMENTO}

\author{
[DES]VELHECER, A SENSORY-SCENIC \\ REFLECTION ON WOMEN AND AGING
}

\section{[DES]VELHECER, UNA REFLEXIÓN SENSORIAL- ESCÉNICA SOBRE LA MUJER Y EL ENVEJECIMIENTO}

\section{Stela Fischer Leticia Olivares}

Stela Fischer

Doutora em Artes Cênicas pela Universidade de São Paulo (USP). Mestre em Artes/Teatro pela Universidade Estadual de Campinas (Unicamp). Autora do livro Processo colaborativo e experiências de companhias teatrais brasileiras (Hucitec, 2010). Professora da Universidade Estadual do Paraná (Unespar/FAP) e do Centro Universitário Belas Artes de São Paulo. Co-coordenadora do coletivo Rubro Obsceno. E-mail: stelafis@terra.com.br

Leticia Maria Olivares Rodrigues Mestre em Artes Cênicas pela USP. Especialista em Dança e Consciência Corporal pelo Centro Universitário das Faculdades Metropolitanas Unidas (FMU). Graduada em Letras pela Universidade Presbiteriana Mackenzie. Co-organizadora do livro Trajetórias em construção - escritos cênicos dos pesquisadores do LAPETT (Prismas, 2016). Integrante do Núcleo Arte Ciência no Palco e co-coordenadora do coletivo Rubro Obsceno. E-mail: leticiaolivares@uol.com.br 


\section{Resumo}

Este texto identifica e analisa a ação cênica [des]velhecer, do coletivo Rubro Obsceno, na cidade de São Paulo. Considerando a análise e cartografia dessa ação - que lança posicionamentos políticos na construção de poéticas cênicas e cujas premissas giram em torno de visibilizar as subjetividades das mulheres a partir de 60 anos -, enfatizamos a importância da reflexão crítica desde o próprio fazer artístico. Para isso, trazemos inspirações dos trabalhos de Tellas, Diéguez e Beauvoir, entre outras. Compartilhamos a experiência de criação enquanto artistas das artes cênicas e, acima de tudo, identificamos os motivos pelos quais ainda se faz necessário promover ativismos feministas.

Palavras-chave: Ativismo feminista, Teatro de mulheres, Ação social.

\section{Abstract}

This study identifies and analyzes the scenic action [des]velhecer, of the Coletivo Rubro Obsceno, in the city of São Paulo. Considering the analysis and cartography of this action-which launches political positions in the construction of scenic poetics, and whose premises revolve around making the subjectivities of 60-year-old, and older, women visible - we emphasize the importance of critical reflection from the artistic-making itself. Considering this, we are inspired by Tellas, Diéguez, Beauvoir, among others. We share the experience of creation as artists of performing arts and, above all, we identify the reasons why it is still necessary to promote feminist activism.

Keywords: Feminist activism, Women's theater, Social action.

\section{Resumen}

El texto identifica y analiza la acción escénica [des]velhecer, del Colectivo Rubro Obsceno, en la ciudad de São Paulo. Considerando el análisis y la cartografía de esa acción -que lanza posicionamientos políticos en la construcción de poéticas escénicas, y cuyas premisas giran en torno a visibilizar las subjetividades de las mujeres a partir de 60 años- enfatizamos la importancia de la reflexión crítica desde el propio hacer artístico. Para ello, traemos inspiraciones de los trabajos de Tellas, Diéguez, Beauvoir, entre otras. Compartimos la experiencia de creación como artistas de las artes escénicas y, sobre todo, identificamos los motivos por los que todavía se hace necesario promover activismos feministas.

Palabras clave: Activismo feminista, Teatro de mujeres, Acción social. 


\section{Introdução}

Compartilhamos aqui a experiência de criação e condução do projeto [des]velhecer, do coletivo paulista Rubro Obsceno, trabalho desenvolvido com não atrizes acima de 60 anos a partir do tema envelhecimento. Falamos sobre nosso trabalho, pautado na criação de poéticas cênicas e ações sociais reivindicadoras da visibilidade das mulheres que resultam em atos estéticos $\mathrm{e}$ políticos. Afinal, para nós, não faz mais sentido realizar uma prática artística que não orientada a um compromisso global, em diálogo com as demandas sociais, em especial as questões dos direitos das mulheres. Assumimos o risco de escrever este texto, tão cheio de pessoalidades, inspiradas pelas orientações da atriz do Odin Teatret, Julia Varley - que, durante os encontros do The Magdalena Project, ${ }^{1}$ do qual é uma das fundadoras, convoca, insistentemente, todas as mulheres artistas a exercer a escrita e a reflexão crítica com base no próprio fazer artístico.

O coletivo Rubro Obsceno é um agrupamento teatral criado em 2013, ${ }^{2}$ na cidade de São Paulo, a partir dos encontros do The Magdalena Project no Brasil. ${ }^{3}$ Composto por mulheres artistas da performance, da dança e do teatro, trata de questões sobre a legitimação de direitos das mulheres no contexto social brasileiro. Juntas, promovemos grupos de estudos sobre a mulher na contemporaneidade; workshops com artistas convidadas; festivais - como a mostra ObsCENAs: Encontro de Mulheres Artistas, em novembro de 2014, que contou com a presença de Julia Varley - e criações artísticas. Por exemplo, estivemos em parceria com a performer mexicana Violeta Luna na

1. The Magdalena Project (1986) é uma rede internacional de mulheres artistas do teatro cuja meta principal é o intercâmbio e incentivo à reflexão crítica sobre a mulher no teatro contemporâneo. Promove encontros periódicos que objetivam agregar mulheres artistas em atividades de intercâmbio de experiências, como workshops, debates, demonstrações de trabalhos e apresentações artísticas. Mais informações no site <www.themagdalenaproject.org>. Acesso em: 4 set. 2018.

2. Compunham o coletivo Rubro Obsceno, até 2014, além de Leticia Olivares e Stela Fischer, as artistas Léia Rapozo e Monica Siedler.

3. No Brasil, temos quatro edições do The Magdalena Project: Solos Férteis - Festival Internacional de Mulheres no Teatro, em Brasília (DF), organizado por Luciana Martuchelli; Multicidade - Festival Internacional de Mulheres nas Artes Cênicas, no Rio de Janeiro (RJ), coordenado por Paola Vellucci; Magdalena $3^{\text {a }}$ Geração, em Jundiaí (SP), com curadoria de Luiza Bitencourt; e Vértice Brasil, em Florianópolis (SC), organizado por Barbara Biscaro, Glaucia Grigolo, Marisa Naspolini e Monica Siedler. 
criação da performance Para aquelas que não mais estão (2015), memorial às vítimas de feminicídio na América Latina e denúncia poético-cênica da violência contra as mulheres. A performance participou da II Bienal Internacional de Teatro da Universidade de São Paulo (USP), em 2015, do X Encuentro do Hemispheric Institute of Performance and Politics (Santiago, Chile, julho de 2016), do Festival Internacional Mujeres en Cena por la Paz (Bogotá, Colômbia, agosto de 2017) e do Ruídos EnCena (Curitiba, setembro de 2017).

Em sua trajetória, o Rubro Obsceno realiza projetos artísticos sociais sob a perspectiva de um teatro voltado ao empoderamento de diferentes grupos de mulheres, como mulheres soropositivas (projeto ++Mulheres, em parceria com a ONG Ecos Comunicação e Sexualidade, 2010-2013), mulheres em situação de violência (parceria com o Centro de Referência da Mulher Casa Eliane de Grammont, 2015), mulheres a partir de 60 anos (projeto [des] velhecer, Sesc Santana, 2016) e mulheres em situação de cárcere (projeto Mulheres Possíveis, com o coletivo Teatro Dodecafônico, ${ }^{4}$ 2016-2018.

A partir dessas ações e trabalhos, o Rubro Obsceno busca desenvolver um campo de experimentação cênica pautada na memória, nas biografias e nos depoimentos pessoais, capaz de evidenciar as histórias pessoais dessas mulheres - que "passam" por nós - e reiterá-las. Como reescrituras, interessa-nos falar de uma arte feita de fissuras e aporias, de hibridizações, sincretismos que convocam identidades de mulheres diversas para tomar o centro das discussões pelos vieses político, ético e poético.

\section{2. [des]velhecer}

Cuanto trabajo para

Una mujer saber

Quedarse sola y envejecer

(Mercedes Sosa e Gloria Martín, Quanto trabajo)

4. O coletivo Dodecafônico (SP) é um conjunto de artistas de várias áreas - teatro, música, performance, artes visuais, dança e arte sonora -, reunidos em pesquisas para a criação artística contemporânea. Mais informações em: <http://teatrododecafonico.blogspot.com. br/>. Acesso em: 4 set. 2018. 
[des]velhecer é um projeto sociocultural de inclusão intergeracional e integra a pesquisa do coletivo Rubro Obsceno sobre temas relacionados às mulheres latino-americanas. Propõe a realização de ações culturais que reúnem residência artística, oferta de oficina, palestra, criação e apresentação cênica com o intuito de abordar uma temática de proeminente relevância na contemporaneidade social brasileira: o processo de envelhecimento, em especial o da mulher. O objetivo principal é trabalhar com não atrizes a partir de 60 anos tendo como meio criativo suas próprias biografias e "linhas do tempo".

\subsection{Origem}

[des]velhecer surgiu como proposta cênica às reflexões sobre as diferentes vivências, impasses e particularidades que as mulheres encontram ao longo do seu envelhecimento, avigoradas pelas questões de gênero nesse processo. A ideia surgiu em 2010, quando o grupo se chamava Magna Mater, ${ }^{5}$ a partir do contato estabelecido com mulheres da terceira idade de diferentes perfis socioeconômicos e, principalmente, com as próprias avós, em busca da compreensão de como é para outras mulheres o processo de envelhecimento.

Segundo Küchemann (2012), o censo em 2010 do Instituto Brasileiro de Geografia e Estatística (IBGE) apontou o envelhecimento dos cidadãos do país. Com $80 \%$ da população recenseada, as projeções indicaram que, em 2020, a proporção de idosos será de 30,9 milhões, ou $14 \%$ do total, sendo que $55,5 \%$ dos idosos brasileiros são mulheres. Portanto, os dados expõem uma feminização da velhice. Ainda, pesquisas mais recentes mostram que "o percentual de pessoas com 60 anos ou mais na população do país passou de $12,8 \%$ para $14,4 \%$, entre 2012 e 2016 . Houve crescimento de $16,0 \%$ na população nessa faixa etária"6

Embora seja comum a ambos os sexos, o envelhecimento é vivido diversamente por homens e mulheres: "Com o envelhecimento, as mulheres são afetadas diferentemente de homens, tornando-as mais vulneráveis não

5. A companhia cênica Magna Mater iniciou suas atividades em São Paulo, em 2008, quando Stela Fischer esteve em parceria com as atrizes Renata Araújo e Tânia Gomes. O grupo desenvolveu estudos, espetáculos e sempre esteve associado a entidades e coletivos feministas.

6. Disponível em: <https://bit.ly/2QICG9o>. Acesso em: 16 set. 2018. 
apenas aos problemas de saúde, mas ao isolamento social e a transtornos emocionais devido à aposentadoria, à viuvez, às alterações fisiológicas" (LIMA; BUENO, 2009, p. 274). Outro fator a ser considerado é que gênero, geração e classe devem ser articulados mutuamente nas discussões, pois a velhice como destino biológico é vivida de maneira variável segundo o contexto social no qual a mulher se insere, como já prenunciado por Simone de Beauvoir em seus livros O segundo sexo, publicado em 1949, e $A$ velhice, de 1970. Nota-se também maior exposição das idosas à pobreza, pois, na sua maioria, seus rendimentos, aposentadorias ou salários são menores em comparação aos dos homens e, em muitos casos, são elas que mantêm ou ajudam no sustento de suas famílias. Outra problemática que se evidencia é a falta de reconhecimento ou direito à aposentadoria por trabalho doméstico, condição que "empurra" muitas mulheres idosas para a condição de dependentes de algum de seus familiares, criando maior vulnerabilidade no seu processo de envelhecimento. Ou ainda, como analisa Simone de Beauvoir (1990), a velhice é o resultado do prolongamento de um processo identitário. E esse processo, em especial o das mulheres, de reconhecimento de si em diferentes momentos da vida nos interessa, pois

Aos 20 anos, aos 40 anos, imaginar-me velha é imaginar-me uma outra. Há algo de amedrontador em toda metamorfose. [...] A velhice é particularmente difícil de assumir, porque sempre a consideramos uma espécie estranha: será que me tornei, então, uma outra, enquanto permaneço eu mesma? (BEAUVOIR, 1990, passim)

Sensibilizadas pelo tema e com o objetivo de valorização do envelhecimento das mulheres, lançamo-nos em pesquisas teóricas e de campo para a coleta de depoimentos a fim de ampliar nosso repertório criativo e possibilidades de diálogos. A documentação foi feita em áudio e vídeo e serviu como material da criação cênica da primeira performance de [des]velhecer. Conversamos com mulheres de 60 anos ou mais e de diferentes perfis socioeconômicos, reunindo material para fomentar a cena a partir de dados reais e biográficos. "Como está sendo o seu processo de envelhecimento?" foi a pergunta guia de nossas conversas. Entramos em contato com queixas que se repetem nos depoimentos sobre a adaptação às mudanças fisiológicas 
decorrentes da idade, a hipervalorização da juventude, o empobrecimento, o isolamento, a falta de relações afetivas e sexuais. A avó paterna de Stela, Nair Campani, com 82 anos na época, por exemplo, lamenta-se: "Me sinto muito sozinha. E a idade traz essas consequências para a gente. Envelhecer me trouxe muitas recordações. Tenho muitas saudades do tempo que passou"7.

Apresentamos a primeira versão de [des]velhecer no Vértice Brasil do ano de 2012, no Sesc Capupé, em Florianópolis. Uma celebração às nossas avós, usando seus vestidos, identificando-nos com elas e traduzindo seus processos de envelhecimento em nossos corpos. Mas ainda, nesse momento, não conseguimos realizar o projeto na íntegra, com a abrangência que desejávamos.

\subsection{Desvelhecendo: seis anos depois}

Março de 2016, mês das mulheres e de muito trabalho para o Rubro Obsceno. Juntas, enfim, realizamos o projeto que nos uniu: [des]velhecer. A convite do Sesc, por meio da unidade Santana (SP), promovemos uma oficina de teatro para mulheres com mais de 60 anos e desdobramos apresentação de espetáculo com elas em cena, narrando suas biografias e linhas de tempo. Eu Ihe confiei a direção do workshop, não tinha a menor dúvida que este projeto teria de ser conduzido por você. Era como o fechar de um ciclo, pois quando nos aproximamos em 2010 foi você quem trouxe a ideia de trabalharmos sobre o envelhecimento. ${ }^{8}$

[des]velhecer seis anos após a ideia original. Chega o momento de realizarmos o projeto em formato de oficina e apresentações. Fomos convidadas para participar da programação da segunda edição da mostra DelGeneradas, do Sesc Santana (SP), que promoveu diversas atividades em celebração ao Dia Internacional das Mulheres durante todo o mês de março de 2016, com ciclos de conversas, performances, exposições, filmes e shows musicais. ${ }^{9} \mathrm{O}$

7. Entrevista verbal concedida a Stela Fischer, São Paulo, 2012.

8. Fragmento de "Carta para Leticia" em $O$ que te prende, mulher? E outras histórias do Rubro Obsceno, apresentado no festival Multicidade (Rio de Janeiro, 2016).

9. Nomes como a filósofa Márcia Tiburi, a funkeira MC Carol e as cineastas Petra Costa e Anna Muylaert foram destaque da programação de DelGeneradas. Foi lembrado o aniversário de dez anos da Lei oㅜ 11.340, de 7 de agosto de 2006 - a Lei Maria da Penha -, evidenciando a vulnerabilidade de grupos de mulheres mais expostas à violência e à morte, como as negras, as periféricas, as lésbicas e as transexuais. 
projeto objetivou a elaboração dramatúrgica e levantamento de material biográfico como campo de experimentação, investigação e criação cênica, em uma abordagem direta com a vida de não-atrizes inscritas na oficina. Foram realizados oito encontros para levantarmos a performance e dois dias de apresentação, tendo as participantes, mulheres a partir de 60 anos, como performers. Todos os exercícios e práticas propostas como atividade na oficina, como os jogos teatrais de integração, sensibilização, aquecimento corporal e vocal e improvisações, foram utilizados para a elaboração das cenas.

Passamos dois meses em intenso contato com um grupo de oito muIheres em seus "envelheceres", ou melhor, "desvelheceres". No caso dessas mulheres, em particular, a velhice, a viuvez, a cura de enfermidades e a volta para a vida social representam libertação: "submetidas durante toda a vida ao marido, dedicadas aos filhos, podem enfim preocupar-se consigo mesmas", conforme Simone de Beauvoir (1990, p. 598) analisa.

Desde o início do projeto, era vivo o desejo de trabalhar as biografias das mulheres em cena, como material dramatúrgico e na construção das ações numa dimensão poética. Inspiradas no procedimento de criação teatral "biodrama”, ${ }^{10}$ da diretora argentina Vivi Tellas (2010 apud GIORDANO, 2013, p. 4) - que defende que "todo ser humano é e traz em si um depósito de arquivos, uma reserva de experiências, conhecimentos, textos e imagens" -, conduzimos uma prática de exploração de relatos, depoimentos e recordações dos momentos de vida mais singulares e definidores, os pontos de virada de suas vidas, para construirmos uma rede de linhas de tempo. Não há construção de personagens, e sim uma abordagem mais direta das biografias. Elas performam a si mesmas.

10. De acordo com o teatrólogo Óscar Cornago (2005), o termo "biodrama" surge de um ciclo de exploração e criação teatral proposto pela diretora argentina Vivi Tellas, quando realizava a curadoria do Teatro Sarmiento, em Buenos Aires, de 2002 a 2009. Foram convidados diretores e dramaturgos da cena contemporânea para construir espetáculos pautados em biografias de pessoas vivas na Argentina. $O$ intuito central era investigar relações entre o real e as teatralidades: "un biodrama consistiría en recrear la vida de estas personas desde una exterioridad anterior a los sentidos lógicos y las preguntas trascendentales impuestas por los discursos culturales, recuperarlas como presencia y apariencia, desde la materialidad hecha visible de sus acciones, gestos y voces resituadas para ello en el plano poético de la escena teatral" (CORNAGO, 2005, p. 12). 
O Biodrama tem como material de inspiração a biografia de uma pessoa viva. [...] Todas as situações biográficas quando colocadas em cena ganham um coeficiente de teatralidade, porque tudo o que é colocado acima do palco (ou em qualquer espaço de representação) se transforma automaticamente em signo teatral. (GIORDANO, 2013, p. 3)

Assim, o procedimento do biodrama nos conduziu para uma prática de exploração de relatos e recordações dos momentos de vida mais definidores para tecer "linhas de tempo". A cena pautada em biografias irrompe uma dimensão poética para a realidade das vidas enunciadas, um instante mágico de autorreferencialidade, um teatro feito de realidades, pois "o biodrama permite encontrar na vida cotidiana personagens comuns e singulares. Essas pessoas são trazidas para o teatro, lugar no qual são representados os seus rituais diários, a partir dos quais as imagens do seu cotidiano íntimo são performadas" (GIORDANO, 2013, p. 4).

Figura 1 e 2 - Não-atrizes em [des]velhecer (São Paulo, 2016). Fotos: Fábio Reginato.
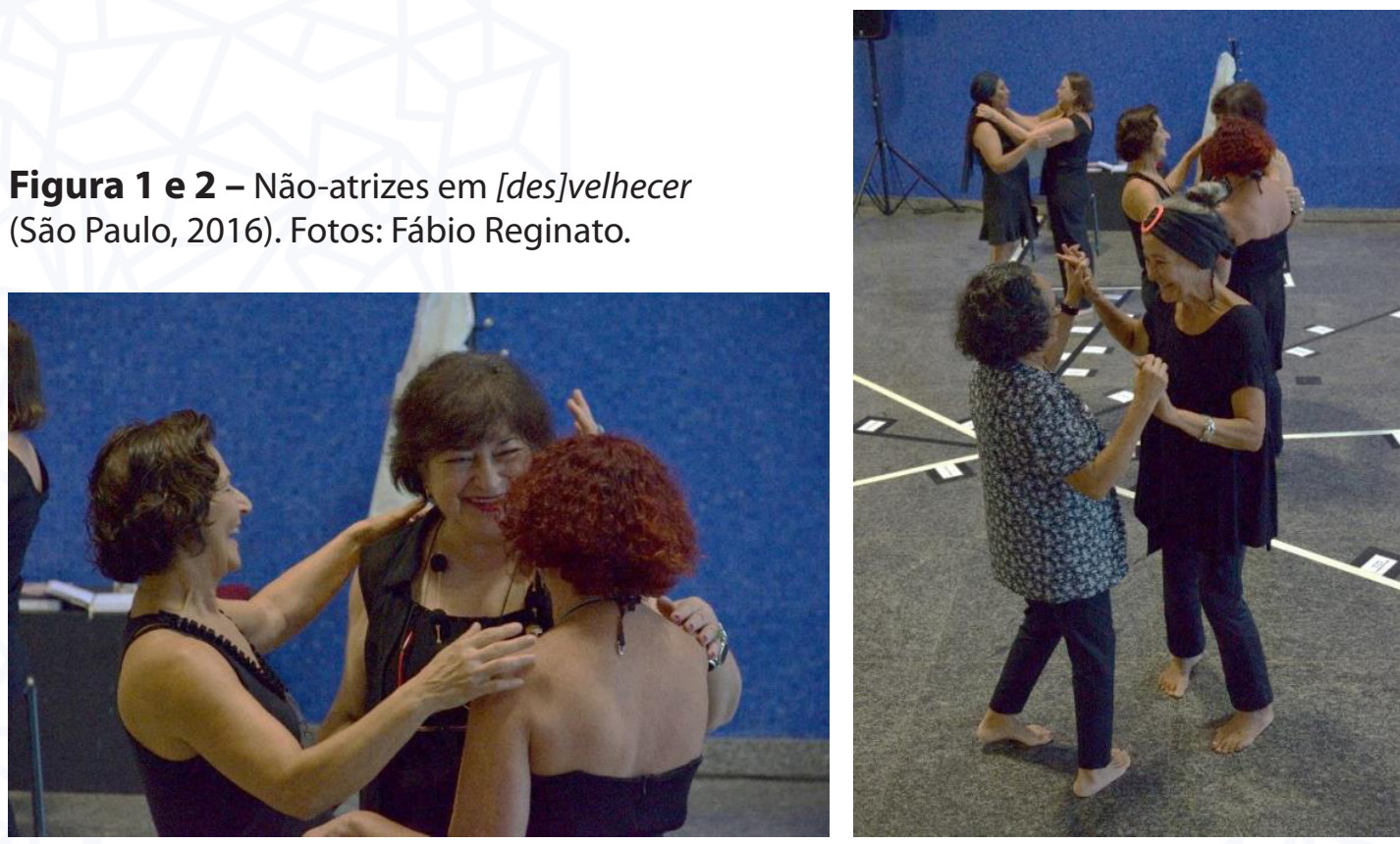

Também solicitamos às participantes que trouxessem objetos de seus universos particulares para ativarmos memórias, ações e teatralidades. Vestidos de quando eram mais jovens, joias que foram dadas como presente por alguém muito estimado, cartas de amor, álbum de fotos do dia do casamento, fotos do esposo, dos filhos e dos netos, roupinhas e sapatinhos de 
bebê e livros que as fizeram crescer profissional e espiritualmente. Objetos como arquivos pessoais, lembranças guardadas pelo tempo e que, em cena, representam a materialização do passado e de toda uma vida construída no tempo. São "objetos/lembrança" ou "objetos-recuerdo", como define Tellas, que servem como

provas de verificação e logo tem a função de sustentar a veracidade das histórias que estão sendo contadas. Os objetos-lembrança marcam a distância de tempo que possibilita a inserção do passado através da narração inscrita no presente. É a concretização material do passado em cena. A narração é o instrumento de atualização da concentração do tempo passado na sua leitura por meio do instante do aqui e do agora da narração presente. (GIORDANO, 2013, p. 9)

Figura 3 e 4. Antonia e Zenaide em [des]velhecer (São Paulo, 2016). Fotos: Fábio Reginato.
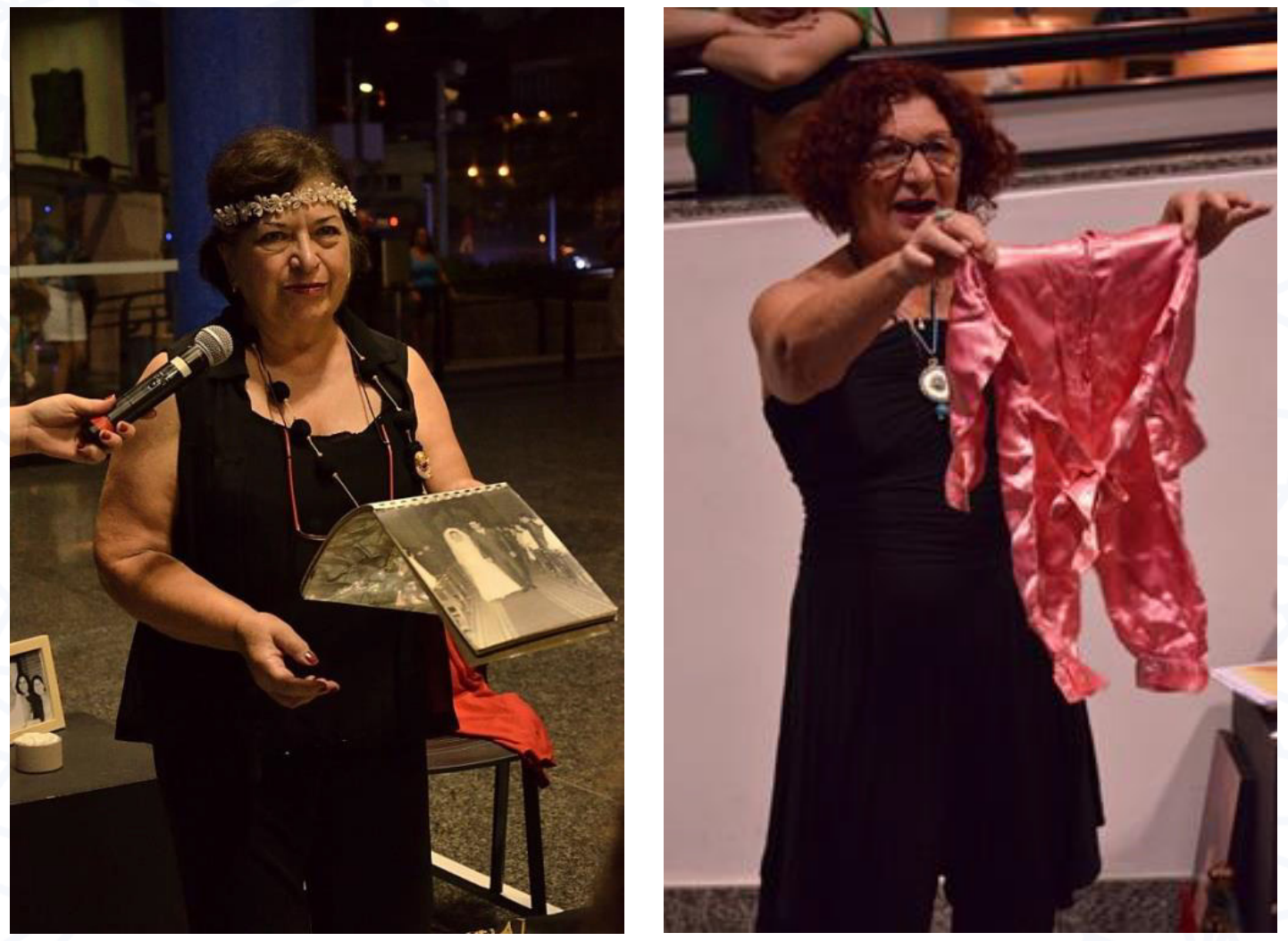

Criamos partituras corporais pautadas nos depoimentos e no manuseio desses objetos. Propusemos que cada uma cantasse suas canções prediletas e escrevesse uma lista de atividades ainda por fazer, de desejos. Assim, a 
partir desses elementos e estímulos, edificamos cenicamente cada uma das biografias, potencializando nas narrativas confessionais sua teatralidade, pois nelas também estão a dança, o canto e as ações realizadas com os objetos, compondo uma dramaturgia de cena do real. De acordo com Tellas (2010 apud GIORDANO, 2013, p. 6):

Uma das maneiras de ativar esta teatralidade mínima nos não atores durante o processo dos ensaios é pedir que os mesmos lembrem de histórias e relatos íntimos. Ela conta que ao repassar as memórias de suas vidas de forma consciente, os não-atores exercitam a repetição que é justamente aquilo que ativa o mínimo de teatralidade. Enquanto isso, a diretora é o único agente criativo da sala de ensaio que possui experiência profissional de palco. Funciona como um experimento científico: a falha está sempre no horizonte do trabalho.

Figura 5. “Altar” de Antonia (São Paulo, 2016). Foto: Fábio Reginato.

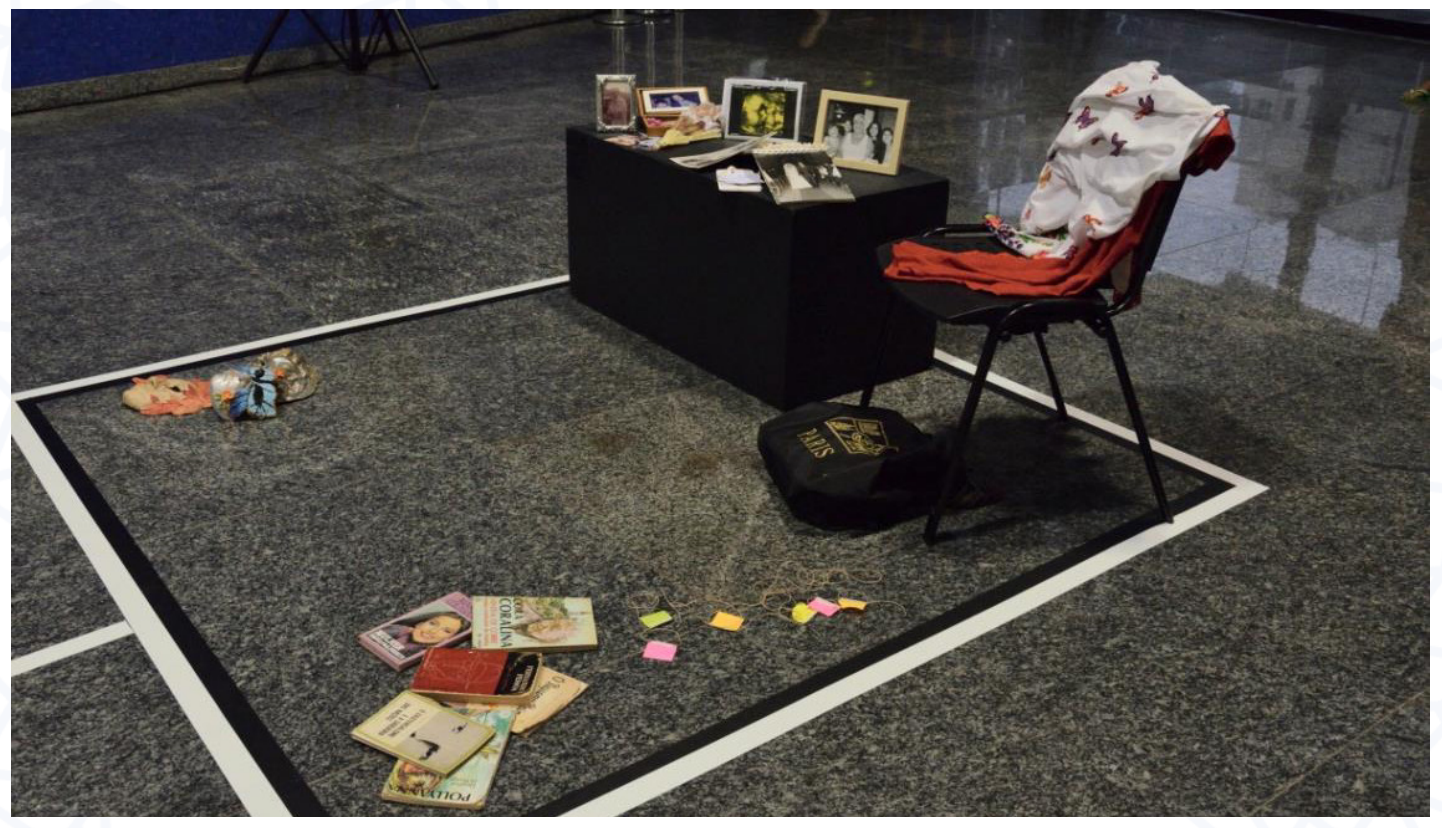

Sete performers, sete linhas de tempo, sete estações. O público é convidado a percorrer uma de cada vez, acompanhando a respectiva trajetória desenhada no espaço, que inicia na data de nascimento e termina em algum acontecimento no tempo presente. A linha do tempo direciona o público até a estação na qual se encontra cada performer em seu "altar,"11 composto por objetos pessoais e por

11. A inspiração para os "altares" ou estações pessoais de cada mulher veio da performance 
meio do qual elas narram a sua história. A dinâmica de o público caminhar até as estações, parar diante delas, aproximar-se e olhar cada detalhe dos objetos que compõem os altares, de escutar de forma íntima as histórias contadas pelas performers e relacionar-se com elas gera uma atmosfera confessional em nossa cena autobiográfica - feita por mulheres em seus [des]velheceres.

Querida Stela, como foi lindo realizar [des]velhecer... Zenaide, Rosires, Espedita, Carmem, Maria José, Delza e Antonia, minha mãe, que também participou do curso e apresentações. Com elas criei partituras corporais, cada uma encenou sua linha do tempo com os momentos mais marcantes das suas vidas e puderam revisitar suas histórias, emocionando o público e se empoderando de suas próprias vozes. Sua confiança na minha condução, também me empoderou e, mais uma vez, notamos o quanto é fluida e complementar a nossa parceria. ${ }^{12}$

\section{Figura 6 e 7. Linhas do tempo de [des]velhecer (São Paulo, 2016). Fotos: Fábio Reginato.}

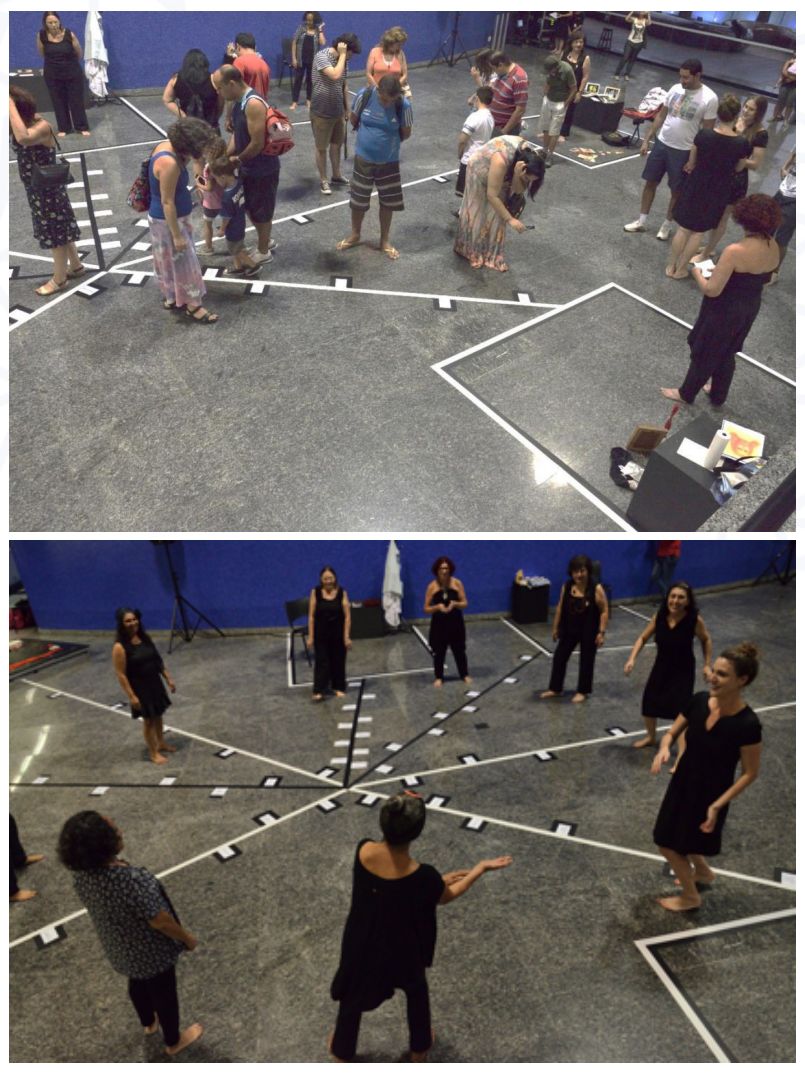

Daughter, idealizada e dirigida por Jill Greenhalgh - artista do País de Gales e uma das fundadoras do The Magdalena Project - no Vértice Brasil (Florianópolis, 2012).

12. Excerto de "Carta para Stela", material da lecture performance O que te prende, mulher? E outras histórias do Rubro Obsceno, apresentada no festival Multicidade (Rio de Janeiro, 2016). 
Em cena, cada uma pode revisitar suas biografias e abrir possibilidades para ressignificar suas vidas a partir do ato de narrar-se. O público, composto majoritariamente por familiares e conhecidos, emociona-se com as narrativas. Há um empoderar-se diante de suas próprias histórias e uma valorização de seus processos de envelhecimento. Vale dizer, nas palavras de lleana Diéguez (2011), que os trabalhos testemunhais irrompem um traço ético, não apenas pela presença física, mas como um sujeito e um ethos que se expõem diante dos outros, muito além da pura fisicalidade. Juntas, criamos uma dimensão poética para a realidade das vidas enunciadas, um instante mágico de autorreferencialidade, um teatro feito de realidades e memórias (re)presentificadas.

Figura 8 e 9. Maria José e Espedita em [des]velhecer (São Paulo, 2016). Fotos: Fábio Reginato.
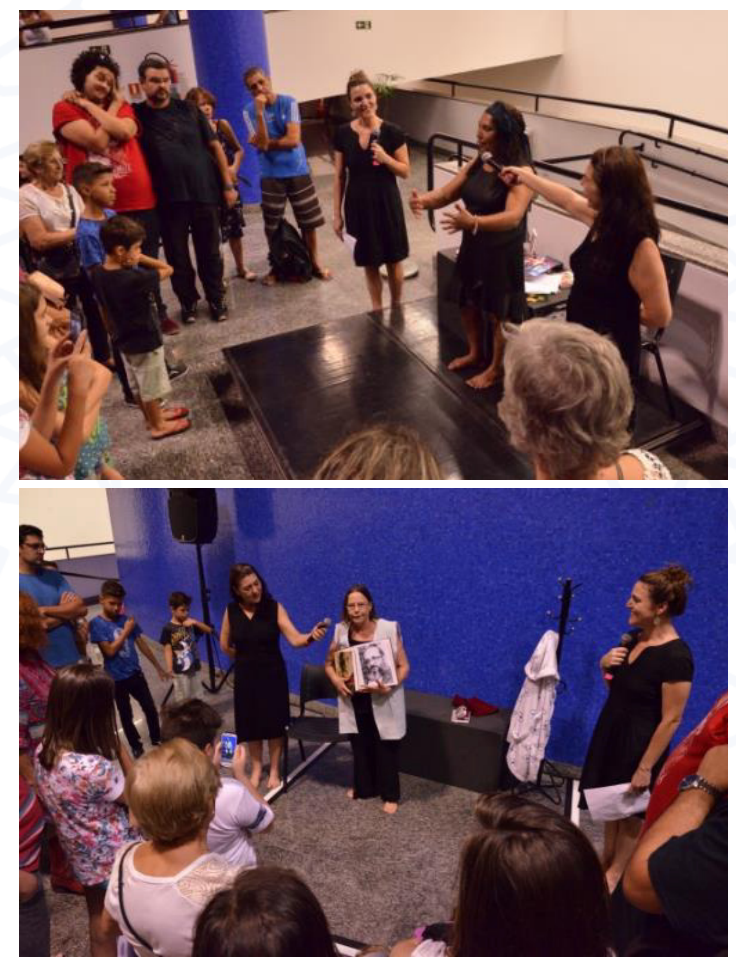

\section{Conclusão}

As ações ao mesmo tempo estéticas e sociais do coletivo Rubro Obsceno estão em defesa dos direitos das mulheres no questionamento dos seus modos de existir como subproduto decorrente de um mercado neoliberal que reforça ainda mais as hierarquias racial, sexual, geracional, econômica e 
cultural. Estamos de acordo com os feminismos que subvertem o binarismo no exercício de práticas libertárias e socializadoras de ideias, conhecimentos e construções de outros mundos possíveis. Aderimos aos feminismos que visibilizam a devastada condição na qual o corpo das mulheres é afetado pela ditadura da beleza com aval do mercado capital das indústrias cosméticas, que traduzem o envelhecer como abjeção. Acreditamos em novas possibilidades estéticas, poéticas e discursivas necessárias para transcendermos a condição de vitimização das mulheres. Articulamos, a partir das nossas criações, outros temas, numa dinâmica capaz de envolver expressões múltiplas, principalmente quando se trata de formas de construção de identidades e subjetividades com valores sociais que desestabilizem as construções dos discursos hegemônicos.

[des]velhecer é um trabalho que abarca o mapeamento cronológico de eventos pessoais na produção de relatos encenados numa performance que destaca trajetórias de vidas e afetividades de mulheres maduras, contando, cenicamente, suas histórias. Esse resumo, essa depuração traz intensidade a cada momento revivido, presentificando, na cena, a experiência. O trabalho com não atrizes é uma opção de micropolíticas de empoderamento da mulher que o coletivo Rubro Obsceno vem perscrutando em sua existência. Desde os trabalhos com mulheres soropositivas até o projeto com mulheres em situação de cárcere, interessa-nos oportunizar, pela linguagem cênica, o protagonismo das vozes e histórias a serem contadas. Antonia, participante de [des]velhecer em 2016, agora prestes a completar 75 anos, contou-nos recentemente que participaria de uma entrevista de emprego e que torcia para que lhe perguntassem sobre um acontecimento importante de sua vida, pois falaria sobre sua participação na performance: "um momento de libertação e afirmação". Temos a preocupação e o cuidado de não sermos porta-vozes de nada - porém, possuímos a firme convicção de que, como artistas e facilitadoras da linguagem cênica, podemos ampliar o alcance das alteridades, colocando-as em evidência em locais de representação e representatividade. 


\section{Referências bibliográficas}

BEAUVOIR, S. O segundo sexo. Rio de Janeiro: Nova Fronteira, 1980a. v. 1. O segundo sexo. Rio de Janeiro: Nova Fronteira, 1980b. v. 2.

A velhice. Rio de Janeiro: Nova Fronteira, 1990.

CORNAGO, Ó. Biodrama. Sobre el teatro de la vida y la vida del teatro. Latin American Theatre Review, Lawrence, v. 39, n. 1, p. 5-28, Fall 2005. Disponível em: <https://bit.ly/2MLv9bV>. Acesso em: 4 set. 2018.

DIÉGUEZ, I. Prácticas de visibilidad: ethos, teatralidad y memória. In: ZAPATA, M. R. El cuerpo ausente (performance política). Lima: Grupo Cultural Yuyachkani, 2008. p. 19-29.

GIORDANO, D. O biodrama como a busca pela teatralidade do comum. Revista Lindes, Buenos Aires, n. 6, p. 1-13, mayo 2013. Disponível em: <https://bit.ly/2wEvwLd>. Acesso em: 4 set. 2018.

IBGE. Instituto Brasileiro de Geografia e Estatística. PNAD 2016: população idosa cresce 16,0\% frente a 2012 e chega a 29,6 milhões. Agência IBGE notícias, 24/11/2017. Disponível em: <https://agenciadenoticias.ibge.gov.br/agencia -sala-de-imprensa/2013-agencia-de-noticias/releases/18263-pnad-2016 -populacao-idosa-cresce-16-0-frente-a-2012-e-chega-a-29-6-milhoes. Acesso em: 16 set. 2018 .

KÜCHEMANN, B. A. Envelhecimento populacional, cuidado e cidadania: velhos dilemas e novos desafios. Sociedade e Estado, Brasília, v. 27, n. 1, p. 165-180, jan.-abr. 2012. Disponível em: <https://bit.ly/2NhdUhS>. Acesso em: 4 set. 2018.

LIMA, L.; BUENO, C. Envelhecimento e gênero: a vulnerabilidade de idosas no Brasil. Rev. Saúde e Pesquisa, Maringá, v. 2, n. 2. p. 273-280, 2009. Disponível em: <https://bit.ly/2wKv1yg>. Acesso em: 4 set. 2018.

Recebido em 21/08/2018

Aprovado em 24/08/2018

Publicado em 22/08/2008 